TO:

U.S. Department of Energy

FROM: $\quad$ Mary Bishop, Grantee \# DE-FG02-00ER6

SUBJECT: S\&T Accomplishment Report

DATE: November 22,2002

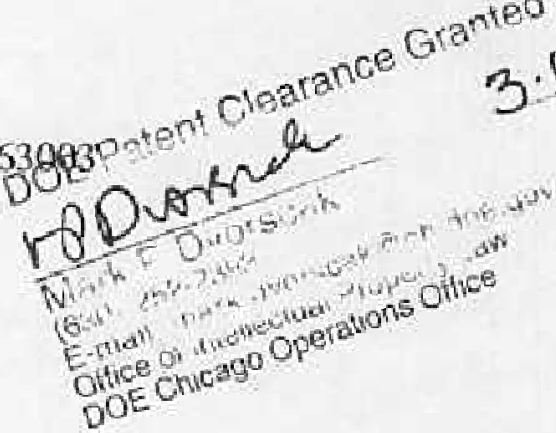

The following report summarizes research conducted in 2001 and 2002 under the above grant entitled "All Not Fit To Breed: Survivors of America's First Eugenics Movement."

The project, carried out by independent scholar and journalist Mary Bishop, set out to locate and obtain interviews with survivors of the eugenics movement in the United States, particularly in the state of Virginia, and with persons familiar with the institutionalization and sterilization of these and other survivors decades ago.

\title{
SURWIVOR INTERVIEWS
}

The researcher succeded in interviewing twelve eugenies survivors unknown to her prior to the DOE-funded stage of her project and in re-interviewing five other survivors discovered earlier by the researcher. The new interviewees bring the total number of survivors interviewed by Bishop to thirty-one (31).

The early weeks of the project, begun in the spring of 2001, were devoted to searching Bishop's earlier compilations of persons institutionalized during Virginia's primary years of eugenics (1920s-1950s) and searching courthouse records and other public sources in order to find the names of persons institutionalized for reasons heretofore unrepresented in eugenics literature, particularly epilepsy.

In April of 2001, Bishop, working from a list of survivors she had assembled from state commitment papers and focusing on patients noted in the record as having epilepsy, found a Newport News woman who confirmed in a telephone interview that she had been placed in the Virginia Colony for Epileptics and Feebleminded in 1949 because she suffered epileptic seizures. The woman also confirmed that she was sterilized there around the age of 20 . She agreed to an interview, but by the time Bishop made the fivehour trip to the woman's home, she had changed her mind. The woman left a note saying that memories of her years at the institution were too painful to revisit and she wished never to be contacted about it again.

(Prompted by the concerns of geneticist Doris Zallen, a member of Bishop's panel of project advisors, and agreeing with Zallen that subjects needed to be able to read about their options prior to being interviewed, Bishop drafted Informed Consent forms and 